\title{
Subspecialized Radiological Reporting Expedites Turnaround Time of Radiology Reports and Increases Productivity
}

\section{Subspezialisierte Befundung beschleunigt die Befunddurchlaufzeit radiologischer Berichte und steigert die Produktivität}

Authors

Christoph Stern ${ }^{1}$, Thomas Boehm ${ }^{1}$, Burkhardt Seifert ${ }^{2}$, Nadine Kawel-Boehm ${ }^{1}$

Affiliation

1 Department of Radiology, Kantonsspital Graubunden, Chur, Switzerland

2 Department of Biostatistics, University of Zurich, Switzerland

Key words

report turnaround time, subspecialized reporting, report availability, reporting workflow, productivity

received 23.06.2017

accepted 17.12.2017

\section{Bibliography}

DOI https://doi.org/10.1055/s-0044-100728

Published online: 15.2.2018

Fortschr Röntgenstr 2018; 190: 623-629

(c) Georg Thieme Verlag KG, Stuttgart · New York

ISSN 1438-9029

Correspondence

\section{Christoph Stern}

Department of Radiology, Kantonsspital Graubunden, Loestrasse 170, 7000 Chur, Switzerland

Tel.: ++41/81/2567606

christoph.stern@gmx.de

\section{ZUSAMMENFASSUNG}

Einleitung Untersucht wurde die Auswirkung eines Wechsels von allgemeiner zu subspezialisierter Befundung auf die Befunddurchlaufzeit radiologischer Berichte (TAT), den Anteil der innerhalb von 24 Stunden freigegebenen radiologischen Berichte $(R<24 h)$ und die Produktivität.

Material und Methoden Der Befundungsworkflow in unserer Radiologieabteilung wurde von allgemeiner Befundung (Radiologen befunden Bilduntersuchungen aus allen Bereichen [neuroradiologische, abdominale, muskuloskelettale Radiologie etc.]) auf subspezialisierte Befundung (Radiologen befunden ausschließlich Bilduntersuchungen aus ihrem subspezialisierten Fachgebiet [z. B.: muskuloskelettale Radiologie]) umgestellt. TAT, $R<24 \mathrm{~h}$ und Produktivität wurden für 12 Monate (Januar-Dezember 2012) allgemeiner Befundung berechnet und verglichen mit einer Periode von 12 Monaten (April 2014-März 2015) subspezialisierter Befun- dung unter Verwendung von Mann-Whitney U-Test, Pearson Chi-Quadrat-Test und der Quotenverhältnisse.

Ergebnisse Die Befunddurchlaufzeit reduzierte sich von median 17:04 Stunden (h) während allgemeiner Befundung auf 3:38 h während subspezialisierter Befundung, was in einer 4,7 -fachen Verbesserung resultierte $(p<0,001)$. Der Anteil der innerhalb von $24 \mathrm{~h}$ freigegebenen radiologischen Berichte verbesserte sich signifikant von $65 \%$ auf $87 \%(p<0,001)$. Die Chance eines radiologischen Berichtes innerhalb von $24 \mathrm{~h}$ freigegeben zu werden war während subspezialisierter Befundung 3,6-fach höher im Vergleich zu allgemeiner Befundung. Die Produktivität verbesserte sich von median 301 auf 376 (Befundberichte/Vollzeitradiologe/Monat) ( $p=0,001)$.

Schlussfolgerung Ein Wechsel des Workflows von allgemeiner zu subspezialisierter Befundung verbesserte signifikant die Befunddurchlaufzeit radiologischer Berichte, den Anteil der innerhalb von 24 Stunden freigegebenen radiologischen Berichte und die Produktivität.

\section{Kernaussagen:}

- Ein Wechsel des radiologischen Befundungsworkflows von allgemeiner zu subspezialisierter Befundung ist praktikabel.

- Die Implementierung subspezialisierter Befundung erbringt eine signifikante Verbesserung der radiologischen Befunddurchlaufzeit.

- Die Implementierung subspezialisierter Befundung verbessert substantiell den Anteil der innerhalb von $24 \mathrm{~h}$ freigegebenen radiologischen Berichte.

- Die Produktivität der Radiologen verbesserte sich nach dem Wechsel auf subspezialisierte Befundung.

\section{ABSTRACT}

Introduction To assess the impact of changing from general to subspecialized reporting on turnaround time of radiology reports (TAT), the fraction of radiology reports available within 24 hours $(R<24 \mathrm{~h})$ and productivity.

Materials and Methods Reporting workflow in our radiology department was changed from general reporting (radiologists report imaging studies of all areas [neuroradiological, abdominal, musculoskeletal imaging et cetera]) to subspecialized reporting (radiologists solely report imaging studies of their subspecialty field [e.g. musculoskeletal]). TAT, R<24 h 
and productivity were calculated for a 12-month period of general reporting (January-December 2012) and compared to a 12-month period of subspecialized reporting (April 2014-March 2015) using Mann Whitney U-test, Pearson chi-square test and odds ratios, respectively.

Results Report TAT decreased from a median of 17:04 hours (h) during general reporting to $3: 38 \mathrm{~h}$ during subspecialized reporting, resulting in a 4.7 -fold improvement $(p<0.001)$. $\mathrm{R}<24 \mathrm{~h}$ improved significantly from $65 \%$ to $87 \%$ ( $<<0.001$ ). The odds of a radiology report being available $<24 \mathrm{~h}$ was 3.6fold higher during subspecialized compared to general reporting. Productivity increased from a median of 301 to 376 (reports/full-time radiologist/month) $(p=0.001)$.

Conclusion Changing the workflow from general to subspecialized reporting significantly improved the turnaround time of radiology reports, the fraction of radiology reports available within 24 hours and productivity.

\section{Key Points:}

- Changing the radiology reporting workflow from general to subspecialized reporting is feasible.

- Implementation of subspecialized reporting yielded significant improvement of radiology report turnaround time.

- Implementation of subspecialized reporting substantially increased the fraction of radiology reports available $<24 \mathrm{~h}$.

- Radiologists' productivity increased after changing to subspecialized reporting.

\section{Citation Format}

- Stern C, Boehm T, Seifert B et al. Subspecialized Radiological Reporting Expedites Turnaround Time of Radiology Reports and Increases Productivity. Fortschr Röntgenstr 2018; 190: 623-629

\section{Introduction}

In an era of decreasing reimbursements for radiologic operations, radiology departments strive to optimize workflow to increase the number of examinations and to gain market share. External referring physicians request short turnaround times for radiology reports (TAT). Reporting times may influence the selection of a radiologic institution [1]. Furthermore, reducing TAT and increasing productivity in a radiology department helps to reduce the length of hospital stay of inpatients and therefore contributes to the overall cost effectiveness of the hospital [1]. It also enables faster clinical decision making and implementation of required therapy. Therefore, there is a concordant demand to expedite radiology report TAT for imaging studies of inpatients and outpatients [1, 2].

According to previous publications, report TATs of up to 24 hours might still be acceptable for outpatient studies [1], while reporting times of less than 8 hours have been described as a “must-have-requirement" for inpatient studies [3]. For emergency department studies, report TATs of $\leq 1$ hour are expected $[1,4]$.

For the last 2 decades there has been a trend towards subspecialization in radiology with an increasing number of subspecialtytrained and -certified radiologists working primarily in their field of expertise, while the importance of a broadly skilled general radiologist has declined $[5,6]$. This trend has been observed not only in academic hospitals, but also in community hospital settings and in private practices. Smith et al. [6] published the results of a survey regarding subspecialization in radiology conducted by the American College of Radiology. $62.9 \%$ of practicing radiologists "reported recent expansions of subspecialization within their practices" [6]. $91.5 \%$ of radiology trainees intend to pursue a fellowship and $89.9 \%$ plan to subspecialize.

Looking for new ways to expedite TAT and to improve performance in our radiology department, we assessed the influence of changing workflow from general reporting (board-certified radiol- ogists report imaging studies of all areas [abdominal, musculoskeletal imaging, etc.]) to subspecialized reporting (board-certified radiologists with subspecialty training solely report imaging studies of their subspecialty field [e.g. musculoskeletal]).

Our hypothesis was that switching from general to subspecialized reporting would expedite the turnaround time of radiology reports, increase the fraction of radiology reports available within 24 hours $(R<24 h)$ and also increase radiologists' productivity.

\section{Materials and Methods}

Performed as a quality improvement initiative, this study was not formally subject to review by the institutional review board.

\section{Department Specifications}

The study was performed at the department of radiology of a 355bed community-based hospital with a radiology resident training program. The radiology department covers all imaging modalities (X-ray including mammography, fluoroscopy, computed tomography $[\mathrm{CT}]$, magnetic resonance imaging [MRI] and ultrasound) and all subspecialties - musculoskeletal, cardiac and thoracic, abdominal, pediatric, neuroradiological, women's imaging and interventional radiology. Throughout the study period, images were interpreted by a constant number of 10 board-certified radiologists and 8 residents.

\section{Workflow}

An integrated RIS (RadCentre: i-Solutions Health GmbH, Mannheim, Germany) / PACS (Centricity: GE Healthcare, Barrington, IL, USA) solution and voice recognition software (SpeechMagic SDK: Nuance Communications, Dublin, Ireland) were successfully implemented long before the study was conducted and all radiologists are familiar with the technique. Since residents do not have permission to sign reports, preliminary reports of residents require final signature of a board-certified radiologist. 


\section{Outcome Measures}

According to the most commonly used definition in the literature, report TAT was defined as "the time from completion of image acquisition until availability of the final radiology report" [7]. TATs were extracted from the RIS using a self-developed calculation tool, which was integrated into the software RadCentre Analyzer (Transact GmbH, Hamburg, Germany). Additionally, the fraction of radiology reports available within 24 hours was calculated. Regarding emergency department studies, a preliminary report is available shortly after image acquisition. However, the TAT was calculated based on the final signature of the radiology report by a board-certified radiologist.

Productivity was defined as the number of generated radiology reports per full-time radiologist (FTR) per month (productivity $=$ reports $/$ FTR/month). To obtain the number of full-time radiologists (=100\% employment), percentages of full-time and part-time employees were cumulated considering absences of four or more successive weeks. Only board-certified radiologists were considered FTRs since they have to provide the final signature for all reports.

For a random sample of 100 radiology reports, the word count was calculated.

Reports of imaging studies completed during core working hours on weekdays (Monday - Friday: 7:30 AM to 5:00 PM) between January 2, 2012 until March 31, 2015 were included in this study. Reports of imaging studies acquired outside core working hours, on weekends and on public holidays were excluded. In rare cases of revision of a finalized radiology report, the date and time of the initial final signature were used for the calculation of the report TAT.

The number of generated radiology reports is substantially lower than the number of examinations performed since the results of two or more exams are frequently integrated into one report, e. g. a combined report for an MRI of the head and neck.

No additional actions such as "pay for performance" procedures were taken to influence TAT and performance.

\section{Reorganization from general to subspecialized reporting}

In 2012 and in the first half of 2013, the workflow was organized as general reporting indicating that board-certified radiologists with or without subspecialty training and residents were assigned to report imaging studies of all areas (abdominal, musculoskeletal imaging, etc.). Board-certified radiologists were assigned to report all imaging studies of a certain imaging modality (X-ray, $\mathrm{CT}, \mathrm{MRI}$ or ultrasound), with weekly rotation from one modality to another. In this system all board-certified radiologists were working as general radiologists. Examinations were performed and reported by only 3 subspecialty-trained and -certified radiologists only in interventional radiology.

Between June 2013 and January 2014, radiological reporting was changed to a subspecialty-based reporting system as a continuous process (implementation period) by first replacing general radiologists with newly employed subspecialized radiologists, second assigning already subspecialized radiologists to their subspecialty field instead of working as general radiologists and third by training and preparing already employed board-certified general radiologists to adopt a subspecialty. In January 2014, reporting was completely changed to subspecialized reporting, indicating that subspecialty-trained board-certified radiologists solely reported and provided the final signature for imaging studies in their subspecialty field (e. g. musculoskeletal) independent of the imaging modality. Each subspecialty was covered by $1-2$ subspecialty-trained board-certified radiologists. Residents continued to be assigned to report imaging studies of all areas. Due to a limited number of staff radiologists, subspecialized reporting was not practicable outside core working hours (Monday - Friday: 5:00 PM - 7:30 AM), on public holidays and on weekends. During the entire study period, potential confounding factors (number of radiologists, technicians, CT and MRI scanners, ultrasound units, case demonstrations per week as well as RIS, PACS and voice recognition software) remained constant.

\section{Statistical Analysis}

Since report TAT was not normally distributed, it is presented as median with interquartile range $\left(25^{\text {th }}\right.$ percentile to $75^{\text {th }}$ percentile). Report TAT of a 12-month period of general reporting (January-December 2012) was compared to a 12-month period of subspecialized reporting (April 2014 to March 2015) using the MannWhitney U-test. Separate analysis was performed for report TAT of $\mathrm{X}$-ray, CT, MRI and ultrasound studies.

The impact on the fraction of radiology reports available within 24 hours was assessed by Pearson chi-square test and odds ratios for both periods. The development of the proportion of radiology reports available $<24$ h over time was evaluated using logistic regression with smooth non-parametric regression line and automatic smoothing parameter selection using package gam [8] in mgcv for R.

With respect to report TAT and $R<24 \mathrm{~h}$, separate analysis was performed for radiology reports generated primarily by residents and finalized by a board-certified radiologist and for radiology reports generated solely by board-certified radiologists for both periods. To assess the homogeneity of the odds ratios, the Breslow-Day test was used.

The productivity of board-certified radiologists during both periods was compared using the Mann-Whitney U-test.

The word count of 100 randomly selected reports of oncological CTs of the thorax and abdomen during the period of general reporting (50 reports) and subspecialized reporting (50 reports) was compared using the student's t-test.

Statistical analysis was performed using SPSS (Version 22, IBM Corporation, Armonk, NY, USA). Significance was assumed for any value of $p<0.05$

\section{Results}

116498 radiology reports of imaging studies completed during core working hours on weekdays between January 2, 2012 and March 31, 2015 were included in this study. 32199 reports were generated during the period of general reporting (January to December 2012) and 38498 reports during the period of subspecialized reporting (April 2014 to March 2015). 


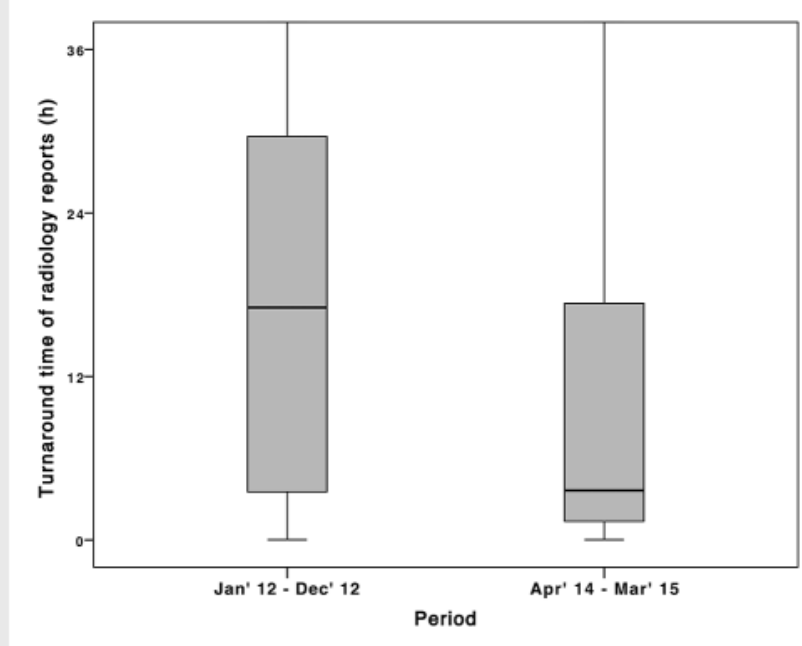

- Fig. 1 Turnaround time of radiology reports (in hours) of all imaging studies presented as median with 25th percentile and 75th percentile during the period of general reporting (January to December 2012) and for the period of subspecialized reporting (April 2014 to March 2015).

- Abb. 1 Befunddurchlaufzeit radiologischer Berichte (in Stunden) aller Bilduntersuchungen, dargestellt als Median mit 25. Perzentile und 75. Perzentile während des Zeitraumes allgemeiner Befundung (Januar bis Dezember 2012) und für den Zeitraum subspezialisierter Befundung (April 2014 bis März 2015).

\section{Turnaround time of radiology reports (TAT)}

The report TAT decreased from a median of 17:04 (3:32 to 29:37) hours (h) during the period of general reporting to 3:38 (1:22 to $17: 22$ ) hours for the period of subspecialized reporting, resulting in a 4.7-fold improvement $(\mathrm{p}<0.001)(\triangleright$ Fig. 1 , $\triangleright$ Table 1$)$. The TAT improved 5.9-fold $(p<0.001)$ for $X$-ray reports, 1.7 -fold $(p<0.001)$ for CT reports, 1.6 -fold $(p<0.001)$ for MRI reports and 5.8 -fold $(p<0.001)$ for ultrasound reports ( $\triangleright$ Table 1$)$. For reports generated primarily by residents and finalized by a board-certified radiologist, the TAT improved 4.1-fold, from a median of 22:39 h to $5: 31 \mathrm{~h}(\mathrm{p}<0.001)$. The TAT of reports solely generated by board-certified radiologists decreased from a median of $6: 28 \mathrm{~h}$ to $2: 16 \mathrm{~h}$, resulting in a 2.9 -fold improvement $(\mathrm{p}<0.001)$.

\section{Fraction of radiology reports available within 24 hours $(R<24 h)$}

Regarding the impact of subspecialized reporting on the availability of radiology reports, the fraction of reports available within 24 hours increased by $22 \%$, from $65.2 \%$ during the period of general reporting to $87.2 \%$ for the period of subspecialized reporting $(p<0.001)(>$ Table 2$) . R<24 \mathrm{~h}$ increased by $28.2 \%(p<0.001)$ for $X$-ray reports, by $11.9 \%(p<0.001)$ for $C T$ reports, by $5.7 \%$ $(p<0.001)$ for MRI reports and by $26.1 \%(p<0.001)$ for ultrasound reports ( $\vee$ Table 2 ). For reports generated primarily by residents and finalized by a board-certified radiologist, $R<24 \mathrm{~h}$ increased by $30.2 \%$, from $54.4 \%$ to $84.6 \%$ ( $p<0.001$ ). $R<24$ h of reports solely generated by board-certified radiologists increased from $73.1 \%$ to $90.9 \%$, resulting in an improvement of $17.8 \%(p<0.001)$.
- Table 1 Turnaround time of radiology reports during general and subspecialized reporting.

- Tab.1 Befunddurchlaufzeit radiologischer Berichte während allgemeiner und subspezialisierter Befundung.

\begin{tabular}{|l|l|l|l|}
\hline $\begin{array}{l}\text { imaging } \\
\text { study }\end{array}$ & $\begin{array}{l}\text { general reporting } \\
\text { TAT (hours) } \\
\text { median (IQR) }\end{array}$ & $\begin{array}{l}\text { subspecialized } \\
\text { reporting } \\
\text { TAT (hours) } \\
\text { median (IQR) }\end{array}$ & $\mathbf{p}^{\mathbf{1}}$ \\
\hline all & $\begin{array}{l}17: 04 \\
(3: 32-29: 37)\end{array}$ & $\begin{array}{l}\text { (1:38 } \\
(1: 22-17: 22)\end{array}$ & $<0.001$ \\
\hline X-ray & $18: 56$ & $3: 12$ & $<0.001$ \\
\hline CT & $(3: 51-34: 16)$ & $(1: 10-16: 15)$ & $<0.001$ \\
\hline MRI & $\begin{array}{l}7: 31 \\
(2: 43-24: 35)\end{array}$ & $\begin{array}{l}4: 26 \\
(1: 40-17: 59)\end{array}$ & $<0.001$ \\
\hline US & $(3: 25$ & $5: 18$ & $<0.001$ \\
\hline & $17: 11$ & $(2: 05-22: 04)$ & \\
\hline
\end{tabular}

Turnaround time of radiology reports (TAT) (in hours) of all imaging studies (all) and different imaging studies (X-ray, CT, MRI, US) presented as median with interquartile range (IQR) during the period of general reporting (January to December 2012) and for the period of subspecialized reporting (April 2014 to March 2015), respectively; CT: computed tomography; MRI: magnetic resonance imaging; US: ultrasound. Befunddurchlaufzeit radiologischer Berichte (TAT) (in Stunden) aller Bilduntersuchungen (all) und von verschiedenen Bilduntersuchungen (Röntgen, CT, MRI, US), dargestellt als Median mit Interquartilsabstand (IQR) jeweils während des Zeitraumes allgemeiner Befundung (Januar bis Dezember 2012) und für den Zeitraum subspezialisierter Befundung (April 2014 bis März 2015); CT, Computertomografie; MRI, Magnetresonanztomografie; US, Ultraschall.

1 Mann-Whitney U-test.

The odds of a radiology report being available within 24 hours was 3.6-fold higher for subspecialized compared to general reporting ( $\vee$ Table 2 ). $\triangleright$ Fig. 2 shows the development of the proportion of radiology reports available $<24 \mathrm{~h}$ over time.

The odds of a radiology report being available within 24 hours was higher for subspecialized compared to general reporting for both reports generated primarily by residents and finalized by a board-certified radiologist and reports generated by board-certified radiologists alone. However, improvement was greater for reports of residents (odds 4.6-fold higher) compared to reports of board-certified radiologists (odds 3.7-fold higher) $(p<0.001)$.

\section{Radiologists' Productivity}

The productivity of board-certified radiologists increased from a median of 301 (290 to 333) (reports/FTR/month) during the period of general reporting to 376 (350 to 407) (reports/FTR/month) for the period of subspecialized reporting $(p=0.001)$ ( $\triangleright$ Fig. 3 ).

The average length of a sample of oncologic radiology reports increased from 229 words during general reporting to 325 words during subspecialized reporting $(p<0.001)$. 
- Table 2 Fraction of radiology reports available within 24 hours during general and subspecialized reporting.

- Tab.2 Anteil der innerhalb von 24 Stunden freigegebenen radiologischen Berichte während allgemeiner und subspezialisierter Befundung.

\begin{tabular}{|c|c|c|c|c|c|}
\hline imaging study & $\begin{array}{l}\text { general reporting } \\
R<24 h \text { (\%) }\end{array}$ & $\begin{array}{l}\text { subspecialized reporting } \\
R<24 h(\%)\end{array}$ & difference (\%) & $\mathbf{p}^{1}$ & $\begin{array}{l}\text { OR } \\
(95 \% \mathrm{Cl})\end{array}$ \\
\hline all & 65.2 & 87.2 & 22.0 & $<0.001$ & $\begin{array}{l}3.6 \\
(3.5-3.8)\end{array}$ \\
\hline X-ray & 61.3 & 89.5 & 28.2 & $<0.001$ & $\begin{array}{l}5.4 \\
(5.1-5.6)\end{array}$ \\
\hline CT & 73.3 & 85.2 & 11.9 & $<0.001$ & $\begin{array}{l}2.1 \\
(1.9-2.3)\end{array}$ \\
\hline MRI & 74.2 & 79.9 & 5.7 & $<0.001$ & $\begin{array}{l}1.4 \\
(1.3-1.5)\end{array}$ \\
\hline US & 64.2 & 90.3 & 26.1 & $<0.001$ & $\begin{array}{l}5.2 \\
(4.5-6.0)\end{array}$ \\
\hline
\end{tabular}

Fraction of radiology reports available within 24 hours $(\mathrm{R}<24 \mathrm{~h}$ ) of all imaging studies (all) and different imaging studies (X-ray, $C T, M R I, ~ U S)$ during the period of general reporting (January to December 2012) and for the period of subspecialized reporting (April 2014 to March 2015), respectively with odds ratios (OR) and $95 \%$ confidence interval (Cl); CT: computed tomography; MRI: magnetic resonance imaging; US: ultrasound.

Anteil der innerhalb von 24 Stunden freigegebenen radiologischen Berichte $(R<24 h$ ) aller Bilduntersuchungen (all) und von verschiedenen Bilduntersuchungen (Röntgen, CT, MRI, US), jeweils während des Zeitraumes allgemeiner Befundung (Januar bis Dezember 2012) und für den Zeitraum subspezialisierter Befundung (April 2014 bis März 2015) mit Quotenverhältnissen (OR) und 95\%-Konfidenzintervall (CI); CT, Computertomografie; MRI, Magnetresonanztomografie; US, Ultraschall.

1 Pearson chi-square test.

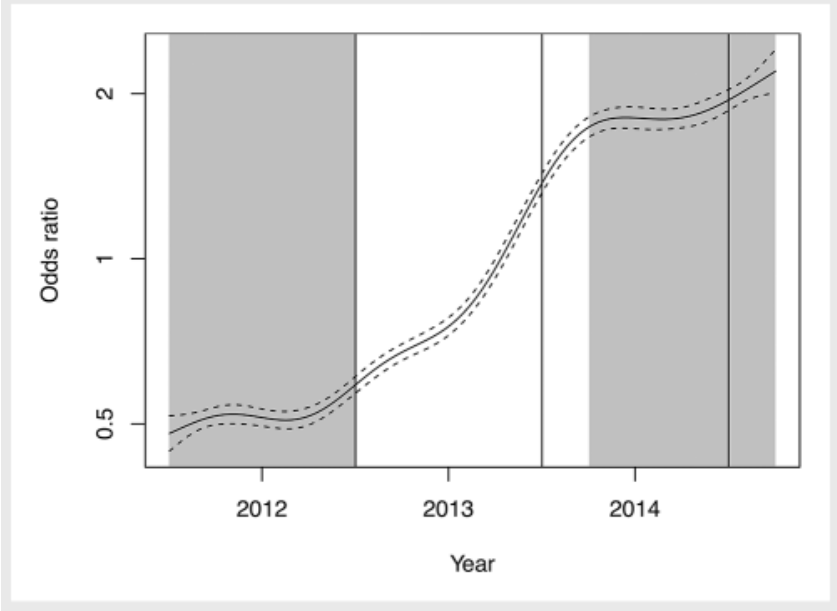

Fig. 2 Development of the proportion of radiology reports available $<24 \mathrm{~h}$ over time. Outcome variable: odds ratio (closed line) with $95 \%$ confidence interval (dashed lines). The odds of a radiology report to be available within 24 hours increased by changing from general reporting (January to December 2012) to subspecialized reporting (April 2014 to March 2015).

- Abb. 2 Entwicklung des Anteils der $<24 \mathrm{~h}$ freigegebenen radiologischen Berichte im Beobachtungszeitraum. Zielvariable: Quotenverhältnis (durchgehende Linie) mit 95\%-Konfidenzintervall (gestrichelte Linien). Die Chance eines radiologischen Berichtes innerhalb von 24 Stunden freigegeben zu werden erhöhte sich nach dem Wechsel von allgemeiner Befundung (Januar bis Dezember 2012) zu subspezialisierter Befundung (April 2014 bis März 2015).

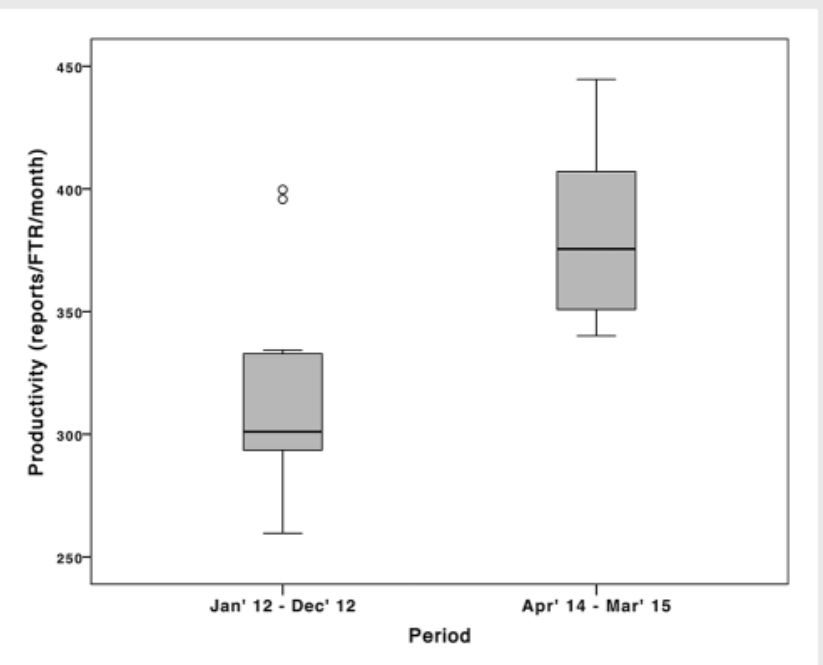

- Fig. 3 Productivity (number of generated radiology reports per full-time radiologist [FTR] per month) presented as median with 25th percentile and 75th percentile of the period of general reporting (January to December 2012) and of the period of subspecialized reporting (April 2014 to March 2015).

- Abb. 3 Produktivität (Anzahl generierter radiologischer Berichte pro Vollzeitradiologe [FTR] pro Monat), dargestellt als Median mit 25. Perzentile und 75. Perzentile während des Zeitraumes allgemeiner Befundung (Januar bis Dezember 2012) und für den Zeitraum subspezialisierter Befundung (April 2014 bis März 2015). 


\section{Discussion}

In our radiology department, changing the workflow from general to subspecialized reporting yielded a statistically significant improvement of the turnaround time of radiology reports, the fraction of radiology reports available within 24 hours and radiologists' productivity.

\section{Turnaround time of radiology reports (TAT)}

We demonstrated that changing from a general to a subspecialized reporting system decreased report TAT by a factor of 4.7 $(p<0.001)$. To our knowledge, there is no prior publication assessing the influence of a change from general to subspecialized reporting on TAT. However, prior publications regarding the impact of voice recognition software (VRS) $[9,10]$ and the impact of a picture archiving and communication system (PACS) [11] on TAT of radiology reports showed similar rates of improvement. Prevedello et al. [10] showed a 5-fold to 24-fold reduction of TAT with the introduction of VRS in a community hospital setting without a residency training program, while Krishnaraj et al. [9] demonstrated a 2.2-fold improvement in an academic institution with radiology trainees. In a study by Mehta et al. [11], the implementation of a PACS resulted in a 6.7-fold decrease in TAT.

According to our experience, the decrease in TAT of subspecialty-trained board-certified radiologists might be explained by the fact that they spend less time on literature search in their daily routine since they are more familiar with the anatomy, pathologies, and post-therapeutic and postoperative conditions. They gain more experience in their field of expertise due to a larger number of imaging studies reported per year. What might be a rare pathology or variant for the general radiologist is more frequently observed and routine for the subspecialized radiologist.

In the current study TATs were reduced substantially for all imaging studies (X-ray, CT, MRI, ultrasound) by implementing subspecialized reporting. However, the effect varied with the greatest reduction observed for $\mathrm{X}$-ray and ultrasound reports and less reduction for $C T$ and MRI reports. This might be explained by the fact that the TAT seems to plateau once a certain level is reached. Since the TATs of CT and MRI studies were rather low already during general reporting (7:31 hours and 8:25 hours, respectively), the potential for improvement was smaller compared to reports of X-ray and ultrasound studies.

\section{Fraction of radiology reports available within 24 hours $(R<24 h)$}

By implementing subspecialized reporting, not only the report TAT but also the fraction of radiology reports available within 24 hours improved substantially by $22 \%(p<0.001)$ with a similar explanation as stated earlier regarding the improvement of the TAT.

Similar to TATs, the improvement was greater for reports of $\mathrm{X}$-ray and ultrasound studies compared to CT and MRI studies. Again, this might be explained by the fact that $R<24 \mathrm{~h}$ seems to plateau once a certain level is reached ( $\boldsymbol{F}$ Fig. 2 ). The improvement of $R<24 \mathrm{~h}$ in this study (5.7\% to $28.2 \%$ ) is similar to the improvement achieved by the introduction of voice recognition software (4.3\% to $20.4 \%$ ) in an academic hospital setting as published by Akhtar et al. [12].

\section{Radiologists' Productivity}

We could show that changing from general to subspecialized reporting also significantly increased productivity, which is most likely a consequence of a reduction in the TAT. Subspecialized radiologists use their time more efficiently compared to general radiologists. Of note, the core working hours were identical during both periods. An increase in productivity was therefore not related to longer working hours but was a result of a true increase in reports generated per radiologist.

\section{Limitations}

Our study has several limitations. First, the study was conducted at a community-based hospital with a radiology resident training program. Results may vary in an academic setting or in a private practice. Since reports primarily generated by residents must be finalized by a board-certified radiologist, the performance of boardcertified radiologists might be underestimated compared to institutions without a radiology resident training program, e. g. private practices. Furthermore, subspecialized reporting cannot be provided by 10 board-certified radiologists during $100 \%$ of the core working hours. During illness, vacation or continuing medical education, staff radiologists had to cover for other subspecialties. However, subspecialized reporting was possible during $91 \%$ of the time due to double coverage of almost all subspecialties.

In the current study the TAT was calculated according to the most common definition in the literature in order to enable comparability with previous publications. However, there are different definitions of TAT. Breil et al. [7] analyzed the calculation of TAT in 37 publications in the radiology domain and identified 11 different time intervals: in 10 publications the definition of TAT was identical to the current study (the time from completion of the image acquisition until availability of the final radiology report). At least 20 publications used different definitions that integrated fewer process steps (e. g. the time from completion of the image acquisition until the beginning of the dictation process [ 6 publications]). In our institution particularly for emergency department studies, preliminary reports are available shortly after image acquisition. However, these preliminary reports were not used for the calculation of TAT.

Due to the nature of the study design, the two reporting systems (general vs. subspecialized reporting) and their influence on TAT, $R<24 \mathrm{~h}$ and productivity had to be tested in consecutive order, allowing other factors that might have changed over the two study periods to influence the results. Separate calculation and comparison of the above performance indicators per individual radiologist was not feasible due to employee turnover (replacement of general radiologists by newly employed subspecialized radiologists), which is a potential confounding factor. It was also not possible to calculate and compare performance indicators per subspecialty since examinations were not assigned to a subspecialty during the first period of general reporting. In retrospect, it cannot be identified whether a $\mathrm{CT}$ of the thorax and abdomen, for example, belonged to musculoskeletal, abdominal, thoracic or vascular radiology. 
However, potential confounding factors (number of radiologists, technicians, CT and MRI scanners, ultrasound units, case demonstrations per week as well as RIS, PACS and voice recognition software) were kept constant over the entire study period to the greatest extent possible.

To avoid bias, there was no change in the resident teaching program or the individual case reading procedure throughout the entire study period. No additional actions such as "pay for performance" were taken to improve TAT and productivity. Also the word count of reports did not decrease from general to subspecialized reporting as a potential confounder. In fact, a comparison of 100 randomly selected reports of oncological CTs of the thorax and abdomen showed a statistically significant increase in word count.

Furthermore, the impact of subspecialized reporting on the quality of reports was not formally evaluated. However, the quality of reports is a critical measurement. According to our impression, there was no inverse association between report TAT and performance, respectively, and quality of reports. This is supported by results of Rosenkrantz et al. [13], who showed weak to no correlation between TAT and report quality (report content, report clarity and impact on patient care). Several publications from different subspecialty areas have even shown increasing quality of reports with subspecialized reporting. For example, Zan et al. [14] found clinically important differences in the reports of $7.7 \%$ of 4534 neuroradiology studies reinterpreted for second opinion by subspecialty-trained neuroradiologists compared to the initial report generated outside the institution usually by radiologists without special training. In a study by Eakins et al. [15], second opinion interpretation of 773 pediatric imaging studies was performed by subspecialists in pediatric imaging. Compared to the original report by general radiologists, major and minor discrepancies were detected in $21.7 \%$ and $20 \%$, respectively. Comparing breast cancer detection rates of general radiologists and breast imaging specialists, Sickles et al. [16] showed that the detection rate was significantly higher for subspecialists for both screening and diagnostic mammography. Bell and Patel [17] reported that the degree of subspecialization of board-certified radiologists performing second opinion interpretation had a significant impact on the detection rate of clinically relevant discrepancies.

In conclusion, changing the workflow from a general to a subspecialized reporting system is feasible and its implementation yields statistically significant improvement in the turnaround time of radiology reports, the fraction of radiology reports available within 24 hours and radiologists' productivity at a communitybased hospital with a radiology resident training program. After reaching a plateau, further investigation is needed particularly to further decrease the number of reports available after 24 hours.

\section{CLINICAL RELEVANCE OF THE STUDY}

- Subspecialized reporting improves workflow and efficiency in a radiology department.

- Expedition of radiology report turnaround time contributes to faster patient management.

- Faster management of inpatients contributes to the economic success of a hospital.

\section{Conflict of Interest}

The authors declare that they have no conflict of interest.

\section{References}

[1] Boland GW. Voice recognition technology for radiology reporting: transforming the radiologist's value proposition. Journal of the American College of Radiology: JACR 2007; 4: 865-867

[2] Boland GW. Stakeholder expectations for radiologists: obstacles or opportunities? Journal of the American College of Radiology: JACR 2006; 3 : $156-163$

[3] Zhang L, Hefke A, Figiel J et al. Identifying radiological needs of referring clinicians. Journal of digital imaging 2013; 26: 393-401

[4] England E, Collins J, White RD et al. Radiology report turnaround time: effect on resident education. Academic radiology 2015; 22: 662-667

[5] Liebscher L, Sherry C, Breslau J et al. The general radiologist in the 21st century. Journal of the American College of Radiology: JACR 2012; 9: $554-559$

[6] Smith GG, Thrall JH, Pentecost MJ et al. Subspecialization in radiology and radiation oncology. Journal of the American College of Radiology: JACR 2009; 6: 147- 159 e144

[7] Breil B, Fritz F, Thiemann $V$ et al. Mapping turnaround times (TAT) to a generic timeline: a systematic review of TAT definitions in clinical domains. BMC medical informatics and decision making 2011; 11: 34

[8] Hastie T. gam: Generalized Additive Models. R package version 1.12. 2015 [cited 2016 2016.01.30]. Available from: http://Cran.R-project. org/package $=$ gam

[9] Krishnaraj A, Lee JK, Laws SA et al. Voice recognition software: effect on radiology report turnaround time at an academic medical center. Am J Roentgenol American journal of roentgenology 2010; 195: 194-197

[10] Prevedello LM, Ledbetter S, Farkas C et al. Implementation of speech recognition in a community-based radiology practice: effect on report turnaround times. Journal of the American College of Radiology: JACR 2014; 11: 402-406

[11] Mehta A, Dreyer K, Boland G et al. Do picture archiving and communication systems improve report turnaround times? Journal of digital imaging 2000; 13: 105-107

[12] Akhtar W, Ali A, Mirza K. Impact of a voice recognition system on radiology report turnaround time: experience from a non-english-speaking South Asian country. Am J Roentgenol American journal of roentgenology 2011; 196: W485; author reply 486

[13] Rosenkrantz AB, Bonavita JA, Foran MP et al. Is there an association between radiologist turnaround time of emergency department abdominal CT studies and radiologic report quality? Emergency radiology 2014; 21: $5-10$

[14] Zan E, Yousem DM, Carone M et al. Second-opinion consultations in neuroradiology. Radiology 2010; 255: 135-141

[15] Eakins C, Ellis WD, Pruthi S et al. Second opinion interpretations by specialty radiologists at a pediatric hospital: rate of disagreement and clinical implications. Am J Roentgenol American journal of roentgenology 2012; 199: 916-920

[16] Sickles EA, Wolverton DE, Dee KE. Performance parameters for screening and diagnostic mammography: specialist and general radiologists. Radiology 2002; 224: $861-869$

[17] Bell ME, Patel MD. The degree of abdominal imaging (Al) subspecialization of the reviewing radiologist significantly impacts the number of clinically relevant and incidental discrepancies identified during peer review of emergency after-hours body CT studies. Abdominal imaging 2014; 39: $1114-1118$ 